\title{
Jovens universitários em silêncio no mundo das informações: casos de liberação
}

\author{
Ivar César Oliveira de Vasconcelos a \\ Adriana Lira ${ }^{b}$ \\ lomar Pirangi Soares ${ }^{b}$
}

\section{Resumo}

Esta pesquisa teve, como objetivo, investigar estratégias de superação da lógica de violência, exclusão e silêncio, aos quais estão submetidos jovens universitários. Esses recebem muitas informações, sofrendo processos educativos dissonantes das proclamadas intenções de desenvolvimento pleno, o que favorece a mencionada lógica. Tidos como não críticos, silenciam. Em vez da educação monológica, a universidade precisa praticar a dialógica. Um estudo de casos múltiplos, em que cada caso único recebeu um nome - coerência, interação, oportunidade, resiliência, compenetração e contextualização - concluiu que os momentos de superação são potenciais estratégias educacionais transformadoras, que levam do discurso à prática, da opressão à esperança.

Palavras-chave: Universidade. Violência. Exclusão. Silêncio. Liberação.

\section{Introdução}

A educação que considera o ser humano em sua capacidade de pensar, sentir e agir articula seus aspectos informativos e formativos. Essa articulação ocorre quando, entre os envolvidos no ato educativo, se conectam conhecimentos teórico-práticos e desenvolvimento humano, gerando a aquisição de conceitos, alteração de atitudes e implementação de ações para mudar realidades. Ao combinar saber-consciência, o estudante encontra sentido no que pensa e faz, preparando-se com seus professores para identificar problemas, aprender a lidar com eles e apresentar soluções. Entretanto, de maneira geral, a mencionada

\footnotetext{
a Universidade Católica de Brasília, Instituto de Ciências Sociais e Comunicação da Universidade Paulista, Brasília, DF, Brasil

b Centro Universitário do Distrito Federal, Brasília, DF, Brasil

c Universidade Católica de Brasília, Brasília, DF, Brasil
} 
articulação tem se mostrado difícil, pois professores e outros membros da escola parecem paralisados pela miscelânea na qual se converteu o atual mundo das informações. Caso continue a persistir esse problema, reforça-se a inflação de informações, em desequilíbrio com a formação, comprometendo cada vez mais o desenvolvimento humano.

Essa inflação, desarticulada da formação do indivíduo, parece sem freios, na educação superior, supostamente favorável à consolidação de processos formativos iniciados na educação básica. $\mathrm{O}$ uso de informações sem sentido pode renegar infinitos saberes das pessoas. Quando, entre professores e alunos, a interação de experiências sociais se baseia na educação mais informativa do que formativa, ambas as partes envolvidas convertem a desinformação de uns e outros em estratégias de controle da fala.

Um cenário assim favorece a violência simbólica, a qual é seguida pela exclusão social e o silêncio. As violências instaladas manhosamente em universidades que priorizam a informação podem ser exemplificadas por discursos já identificados nesses contextos educacionais: "O aluno vive dando rasteira no professor; acho mesmo que eles são preguiçosos..." (dito por professor); "durante o curso, a universidade vai te empurrando igual a um lixo; o sexto ano é a lixeira" (dito por estudante) (VASCONCELOS; GOMES, 2017, p. 214). O docente que ordena seu aluno a calar a boca e, pior, fazendo-o diante de colegas, parece sentir-se em segurança para fazer isso porque entenderia saber mais do que todos. Efetivamente, isto é violência disseminada em instituições que parecem esquecidas do direito humano à liberdade de pensamento, à opinião e à expressão (ONU, 1998).

Com tal disseminação da violência, abrem-se as portas para a exclusão social de alunos. Esses passam a ser classificados em termos sociais, porquanto a universidade promove a seleção arbitrária do tipo de cultura a ser internalizada por eles. Nessa instituição, com o tempo, gera-se a preocupação, quase exclusiva, com as demandas do mercado de trabalho - a educação superior atende a esse mercado, transmitindo uma pletora de conteúdos; no entanto, isto é uma forma anacrônica de preparo, visto que a discussão, a crítica e a criação situam-se como essenciais para ocupações de nível superior. Assim, no âmbito da universidade, alimenta-se a exclusão diferida de estudantes que, antes da chamada democratização, estavam fora da educação superior, pois, sendo classificados conforme padrões culturais médios, passam a compor um verdadeiro exército de excluídos. É, de fato, a transição da violência à exclusão. 
Com o par violência-exclusão, nocivo consórcio que prejudica a manifestação de subjetividades, chega-se ao silêncio de estudantes. Impacta-se o desenvolvimento desses. Ainda nos momentos de rara interrupção desse silêncio, os alunos são desconsiderados, despercebidos, como se ficassem invisíveis. Portanto, silêncio aqui significa a ausência de liberdade de expressão da capacidade humana de conhecer, fazer, conviver e ser, nos moldes da metáfora dos quatro pilares da educação para o século XXI (DELORS et al., 1998).

Esse silêncio é mola propulsora da educação bancária (FREIRE, 2011) que, retroalimentando-se, passa a calar vozes e consciências. Trata-se de uma posição educativa que transforma o ser humano numa coisa, propondo e viabilizando o processo educacional como o ato constante de depositar conteúdos, em que o depositante se transfigura num educador e o depositário num educando. É o ato de estocar informações. Estabelece-se tal dinâmica no pressuposto de que é possível colmatar a mente humana, esta, supostamente repleta de fendas por onde circulariam informações a valer. Os tentáculos dessa posição educativa costumam abraçar sorrateiramente o dia a dia da relação aluno-professor, indo se estabelecer na sala de aula e demais ambientes de formação. No limite, ela domestica o ser humano na medida em que pressupõe, no processo educativo, ação ativa apenas por parte do professor, e passiva por parte do educando.

Entretanto, como se fosse o outro lado da mesma moeda, a pedagogia dialógica promove a radicalidade da libertação, a quebra do silêncio que, sutilmente, terá se infiltrado no ato educativo. Tal pedagogia se caracteriza pela presença do diálogo como relação horizontal, sedimentando a confiança dos envolvidos nesse ato. $\mathrm{O}$ diálogo estabelecido guarda profunda correspondência com algumas características humanas, tais como a capacidade de pensar, sentir, agir e transcender. Efetivamente, a pedagogia dialógica pressupõe que a educação é momento do percurso de humanização dos indivíduos (FREIRE, 1969).

À vista disso, contrapondo-se à educação bancária, a pedagogia dialógica contribui para que alunos consigam superar a lógica da violência, exclusão e silêncio e, assim, poderem expressar-se com relação ao seu desenvolvimento humano. Quais seriam as estratégias de superação utilizadas por estudantes, em contextos de alta priorização das informações, de modo a liberá-los da mencionada lógica? A pesquisa buscou investigar essas possíveis estratégias, visando descobrir como ocorre tal superação por meio da pedagogia dialógica, a fim de entender como concretizar a liberação desses indivíduos. Espera-se contribuir com reflexões a respeito do problema e com soluções práticas para romper a nociva lógica em 
universidades que privilegiam aspectos informativos, portanto, sem articulá-los com os formativos.

\section{Da violência ao silêncio}

A universidade tem sido menos um bem cultural, mais um bem econômico (BAUMAN, 2007; ENGUITA, 2016). Ancora-se fortemente na instrumentalidade de profissionais, priorizando o desenvolvimento de habilidades e competências adaptadas às mudanças técnicas que renovam a competitividade do mercado de trabalho. Com empenho, tem buscado acompanhar exigências do mundo financeiro e do trabalho em geral, envolvendo-se demasiadamente em aspectos técnicos, ou seja, com ênfase na informação, e negligenciando o desenvolvimento humano como um todo. Este exige o cumprimento do direito à expressão, nem sempre observado, por exemplo, na sala de aula.

Em geral, na universidade, parece haver uma tendência de negar o direito humano à liberdade de expressão postulada, entre outras, pela Declaração Universal dos Direitos Humanos (ONU, 1998, art. 18-19). O direito de procurar, receber e transmitir informações, bem como ideias, pressupõe o direito à liberdade de pensamento, consciência e religião. Entretanto, o exercício deste último nem sempre se faz acompanhado do primeiro. É o caso quando um universitário, tendo ideias e opiniões sobre certo assunto, não consegue expressá-las. Com efeito, já as críticas freireanas realizadas no contexto da problemática educacional brasileira explicitam a dependência do processo educacional à liberdade do educando. Com esta, ele se motiva e assim manifesta suas opiniões e críticas, fazendo-o porque conquistou o direito de manifestá-las (FREIRE, 1996). Logo, retirar esse direito é ato de violência!

A respeito desta, um conceito ainda não é consenso. Ela remete para diversificados contextos históricos e culturais, dependendo do lugar onde se desenvolve e de outros fatores (GOMES; LIRA, 2010). Pode envolver danos físicos (assassinatos, agressões, sequestros) ou simbólicos (preconceito, humilhações, bullying, ironias), estando presente em espaços sociais como o da educação. Com alguma frequência, é cometida por professores.

Em Foucault (2014), violência de professores é instrumento do poder utilizado para disciplinar. Para o autor, alunos se habituam com este poder e o legitimam. Até justificam a punição que sofrem. Dessa maneira, espalha-se o poder e, em seu nome, comete-se violência simbólica - como o "cala a boca", a "ameaça de expulsão da sala de aula", o "olhar de desprezo". Esta é definida por Bourdieu (1994, p. 25) como "uma forma de violência suave, uma vez que nela estão 
encobertas as relações de poder que regem os agentes e a ordem da sociedade global". A legitimidade dos valores produzidos e administrados pela classe dominante resultaria do desconhecimento social, por parte dos dominados, do espaço onde ocorre a luta de classes pelo poder.

Além disso, sendo dialética a relação violência-poder, não apenas o poder se legitima, mas a própria violência desponta como se ela fosse algo natural. A ação pedagógica, de acordo com Bourdieu e Passeron (1992), tem a autoridade conferida por classes que impõem o arbitrário cultural. Assim, passa-se a disseminar a cultura a ser internalizada pelos alunos, deixando de fora quem não a internalizou. Essa é uma maneira violenta de comunicar-se, quando, então, o professor não percebe que sua atuação didático-pedagógica está inserida numa configuração social mais ampla. Assim, a violência se converte em processo de exclusão humana!

Os excluídos, segundo Xiberras (1996, p. 22), "são todos aqueles que são rejeitados de nossos mercados, materiais ou simbólicos, de nossos valores". Nesse sentido, estar excluído é ficar à margem, sem participar da vida social. Logo, desconsidera-se a existência humana; a exclusão, tal como a violência, silencia. É o império do silêncio! Que silêncio é esse, o do meio acadêmico, passível de comparação com uma ausência humana? Onde inicia o seu enfrentamento?

Ele está nos diversos espaços e tempos da chamada sociedade líquida, a qual tem colocado sobre os ombros dos indivíduos, cada vez mais, a responsabilidade pela construção de sua identidade (BAUMAN, 2005; DUBET, 1994; HALL, 2011). Igual a um puzzle, universitários se reconstroem num infindável processo de assimilação e separação (BAUMAN, 2005). Esvai-se a possibilidade da crítica. Quando esta existe, em momentos raros, ainda assim não é considerada. Traduzida em silêncio, é parte perdida do ser humano. É recorte da humanidade deixado para trás, porquanto, julgar e posicionar-se são características humanas. É uma ausência que, no nível ontológico, pode levar à solidão profunda - como em Fernando Pessoa (PAZ, 1976).

\section{Do silêncio à liberação}

Uma das finalidades da educação superior é estimular o pensamento reflexivo (BRASIL, 1996) e sua manifestação. Na sala de aula, por exemplo, não pode o professor achar-se o dono da verdade, esquecendo-se da liberdade de expressão. Não cabe a ele, em monólogo, para cumprir regras institucionais e atender a alguma tendência ao autoritarismo, fechar-se na transmissão de informações. Já os alunos, nesse contexto de violência e exclusão humana, não podem deambular 
sem sentido numa escola que, tendo seguido essa linha de atuação, aprendeu a ensinar, mas não a aprender.

Tal exclusão se intensifica na universidade, pois grande parte dos estudantes, muitos deles jovens (ONU, 1981), traz consigo, desde a educação básica, o gérmen do silêncio, em que o professor, aquele que manda na sala de aula, ensina e, o aluno, aquele que aprende para cumprir etapas, busca quase exclusivamente concluir seu curso e garantir o diploma. Abertamente, o silêncio se reforça no esvaziamento de conteúdo, símbolo novo vendido como antigo. Arrefece-se a reflexão sobre os processos de desenvolvimento pleno (BRASIL, 1996).

Constata-se, pois, que o problema dessa lógica da violência-exclusão-silêncio é o desafio da liberação do ser humano. Emerge a proposta da pedagogia do oprimido, mais tarde reencontrada na pedagogia da esperança (FREIRE, 2011, 2015). Curiosamente, situa-se na ação estudantil o encargo reservado pela filosofia da educação freireana aos oprimidos: o de serem o portal de saída da opressão.

Essa filosofia remete para a dialética do senhor e do escravo (HEGEL, 2003). Os que oprimem e os que sofrem a opressão devem debelar a contradição presente na relação entre os dois. Esta é contraditória, pois, enquanto seres humanos, com a vocação de "ser mais", opressor e oprimido se encontram cativos num circuito que os torna "menos". Segundo Freire (2011), o primeiro deles não tem a força de libertação possuída pelo segundo, pois este se encontra mais preparado para compreender situações opressivas na medida em que vivencia os seus efeitos e a necessidade de tornar-se livre. Para o autor, cabe superar a Pedagogia do Oprimido, com destino à Pedagogia da Libertação.

Portanto, a liberação virá com a prática do diálogo. Para Freire (1996, p. 105), "a liberdade amadurece no confronto com outras liberdades". Consoante o autor, o educador que dialoga não receia apostar na liberdade, na esperança, na palavra advinda do outro, no desejo deste de erguer-se ou reerguer-se. Portanto, por meio do diálogo, se resolverá a tensão dissimulada na ação docente, e institucional, detectada pelo autor, que é o equilíbrio tenso entre autoridade-liberdade, o qual, correntemente, deixa de existir em prol do autoritarismo-licenciosidade.

Nesse sentido, emerge a proposta da Pedagogia Dialógica, segundo a qual, o diálogo é o encontro entre seres humanos, a atitude de tornar-se presente "ao" ser e "com" o ser (BUBER, 1982; FREIRE, 2011). Está em jogo o rearranjo da Paideia e Politeia, como um dia estiveram juntas, em Aristóteles ([séc. IV a. C.] 1996) - efetivamente, a articulação entre aspectos informativos e formativos 
da educação. Neste trabalho, essa articulação é compreendida como o ato educativo que aproxima conhecimentos teórico-práticos e desenvolvimento humano, caracterizando-se, desse modo, maior amplitude desse ato em relação a conhecimentos. Tem como pano de fundo a integração entre saber e consciência concretizada com o uso de princípios capazes de organizar saberes, favorecendo o diálogo, com a emergência de sentidos e o desenvolvimento de competências para identificar e lidar com problemas.

Constata-se que, em vez da educação baseada no monólogo, a universidade precisa pensar e colocar em prática a educação dialógica. Esta, sem abrir mão dos rigores técnicos do preparo profissional, impulsiona, por meio da interação entre experiências sociais (DUBET, 1994; VASCONCELOS; GOMES, 2016), as diversas possibilidades para o desenvolvimento humano. Com a educação dialógica, os envolvidos podem firmar suas identidades na crítica cognitiva e normativa. $\mathrm{O}$ ato educativo volta-se para a formação profissional e cidadã, buscando-se a emergência do sujeito questionador. Ao estudante, possibilita-se a análise da didática, da avaliação, das técnicas, da organização dos trabalhos. Alicerça-se o direito à crítica, à aceitação ou à recusa a valores e interesses, à construção de representações culturais (VASCONCELOS, 2017). Desse modo, saindo da frágil articulação entre informar-formar em direção ao diálogo entre saberes, o educador revela, nesse percurso, sua preocupação em não cometer violências ou excluir os educandos. Da opressão à esperança, concretiza-se a troca do silêncio pela liberação.

\section{Método}

Realizou-se uma pesquisa qualitativo-exploratória, delineada como estudo de casos múltiplos (YIN, 2010), com aporte teórico em Merriam (1998), a qual sintetiza ideias tendentes ao positivismo, presentes em Yin (2010), e ideias existencialistas-construtivistas, presentes em Stake (2016). Desse modo, a pesquisa aponta para um estudo misto. A autora considera o caso uma unidade, cujas fronteiras são limitadas e o estudo de caso a análise de determinado fenômeno, podendo ser, por exemplo, uma instituição, um processo ou uma unidade social neste estudo, o traço característico mais evidente de cada participante, identificado com a pesquisa, acabou por definir um estudo de caso único e assim por diante. Esse tipo de delineamento atendeu ao perfil do objeto de pesquisa, o qual se estabelece em contextos sociais reais, atuais e difusos.

Estes foram compostos por três instituições de educação superior que, instaladas no Distrito Federal, desenvolvem atividades universitárias; sendo duas particulares e uma pública. Selecionaram-se jovens estudantes, pois, em geral, a faixa etária 
a que pertenciam favorece o controle de sua fala pelos professores - a maioria acabou de ingressar na educação superior, trazendo resquícios vivos da ausência da escuta efetiva. Foram dois estudantes de cada uma das instituições, escolhidos não aleatoriamente, e sim a partir de informações sobre seus perfis: alunos com decidida atitude de eliminação do silêncio, frequentemente, imposto por professores, "assessorados" por outros membros e estruturas da escola (ver Quadro 1).

Os seis jovens universitários fizeram relatos de vida (BERTEAUX, 2005), gênero de entrevista coerente com o tipo de estudo de caso assumido, uma vez que foram contadas experiências situadas em tempo e espaços definidos, focalizadas no objeto de pesquisa - as estratégias de superação do silêncio no ambiente acadêmico. Os participantes foram abordados com as seguintes introdução e perguntas: "Sofrendo violência e exclusão, muitos alunos se calam. Alguns conseguem falar, mas não são ouvidos. Poucos são persistentes, dando opiniões sobre sua formação, embora correndo o risco de serem 'marcados' pelo professor. Para você, o que têm de especial esses alunos e alunas? No seu caso, o que o(a) faz abrir a boca e dizer o que pensa? Alguns professores contribuem para essa liberdade de falar?".

Quadro 1. Os casos únicos e os perfis dos participantes.

\begin{tabular}{|c|c|c|}
\hline \multicolumn{2}{|l|}{ Casos } & $\begin{array}{l}\text { Perfis: o contexto educacional/curso/ } \\
\text { sexo/idade }\end{array}$ \\
\hline $\begin{array}{l}\text { Caso 1: } \\
\text { Coerência }\end{array}$ & CEN & $\begin{array}{c}\text { Medicina, } 1^{\circ} \text { semestre. Tem licenciatura } \\
\text { em Educação Física, concluída em } 2011 \\
\text { na instituição pesquisada. M/27. }\end{array}$ \\
\hline $\begin{array}{l}\text { Caso 2: } \\
\text { Interação }\end{array}$ & CEN & $\begin{array}{c}\text { Engenharia Civil, } 3^{\circ} \text { semestre. } \\
\text { Bacharelado em Arquitetura e Urbanismo } \\
\text { concluído em } 2012 \text { na instituição } \\
\text { pesquisada. F/26. }\end{array}$ \\
\hline $\begin{array}{l}\text { Caso 3: } \\
\text { Oportunidade }\end{array}$ & PAR & $\begin{array}{l}\text { Egresso do curso de Administração, } \\
\text { concluído em 2016. M/24. }\end{array}$ \\
\hline $\begin{array}{l}\text { Caso 4: } \\
\text { Resiliência }\end{array}$ & PAR & $\begin{array}{c}\text { Egresso do curso de Comunicação } \\
\text { Social-Jornalismo, concluído em } 2016 . \\
\text { F/25. }\end{array}$ \\
\hline $\begin{array}{l}\text { Caso 5: } \\
\text { Compenetração }\end{array}$ & PUB & Matemática, $4^{\circ}$ semestre. M/22. \\
\hline $\begin{array}{l}\text { Caso 6: } \\
\text { Contextualização }\end{array}$ & PUB & Psicologia, $10^{\circ}$ semestre. $\mathrm{F} / 22$. \\
\hline
\end{tabular}

Fonte: elaboração dos autores (2017).

Legenda: F: Feminino. M: Masculino. CEN: Centro universitário. PAR: Universidade particular. PUB: Universidade pública. 
Os áudios obtidos com as entrevistas foram ouvidos pelos pesquisadores. $\mathrm{Na}$ sequência, elaborou-se um "escrito, com as ideias-chave e episódios apreendidos" (STAKE, 2016, p. 82) nos relatos. O material escrito passou pela análise de conteúdo (BARDIN, 2009), tendo sido, cada relato, um evento pontual e significativo do processo de vida de cada participante (BERTAUX, 2005), concluindo-se a análise com um cross-case (YIN, 2010), coerente com a escolha do tipo de pesquisa.

Tendo essa escolha recaído sobre um estudo de casos múltiplos holístico (YIN, 2010), considerou-se uma só unidade de análise, efetivamente, como eixo central do problema de pesquisa: estratégias de superação da lógica violência-exclusão-silêncio em contextos de priorização dos aspectos informativos da educação. Essa unidade pôs sob o mesmo olhar aspectos particulares de cada um dos casos, enquanto o conjunto destes direcionou o olhar dos pesquisadores para as perspectivas teóricas postuladas pelos quatro pilares da educação para o século XXI, pela pedagogia dialógica (DELORS et al. 1998; FREIRE, 2011), bem como por outros referenciais acrescentados durante as análises. Com estas delimitações, obteve-se uma visão geral de cada caso e de seu conjunto, sendo que os casos únicos tiveram denominações específicas, cada uma delas escolhida com base na característica do estudante mais favorável à mencionada superação: Coerência, Interação, Oportunidade, Resiliência, Compenetração e Contextualização.

\section{Coerência e interação}

Para os dois primeiros casos, Coerência e Interação, tomaram-se os relatos de um aluno e uma aluna que se graduam na mesma instituição, local em que já haviam concluído outro curso. Caracterizou-se, portanto, a dupla experiência acadêmica desses participantes no contexto educacional pesquisado. Em consonância com a sua denominação, no primeiro caso, o participante utiliza a coerência como estratégia de eliminação do silêncio imposto aos estudantes. Sendo de uma família de professores, o estudante relatou várias situações do dia a dia escolar em que se sente silenciado, cabendo citar uma delas que, como as demais mencionadas neste trabalho, não se constitui simples incidente, e sim parte de um processo de silenciamento mais amplo. O exemplo serve também para descrever como a estratégia da coerência é acionada quando o participante precisa sair do silêncio:

Uma professora, com muitos discursos moralistas, tinha algumas regras [como não chegar atrasado após cinco minutos depois de iniciadas as apresentações de alunos na aula]. Então, um dia cheguei 
atrasado e não pude participar da apresentação de meu grupo. Entrei e fiquei na sala. Passaram-se quase trinta minutos e uma colega chegou atrasada... Aí, a professora a deixou entrar e participar da apresentação do grupo dela. Eu levantei a mão e começou um bate-boca porque eu falei 'por que a senhora tá deixando?' Ela perguntou para mim ‘você tem formação militar, é?' No final da aula eu falei 'isso aqui é totalmente incoerente [...] no ambiente escolar você tem que dar o exemplo'.

Durante esse relato, o estudante argumentou que a professora era muito rígida (horário de chegada à sala de aula, por exemplo), tendo sido incoerente em sua atitude e um mal exemplo de educador, embora o participante tenha dito concordar plenamente que deva haver regras e que estas devem ser cumpridas. Evidencia-se, nesse episódio, que predomina como questão de fundo o problema da incoerência entre o discurso e a prática, analisado há quase cinquenta anos por Teixeira (1976) no contexto de suas denúncias com relação à educação brasileira em alguns de seus graves problemas histórico-culturais. Encontrase na base de seculares problemas da educação no Brasil a substituição corriqueira dos valores proclamados pelos valores reais, caracterizando um distanciamento entre o dito e o realizado - uma hipocrisia organizacional (BRUNSSON, 2007). Diante desse relato, cabe lembrar que, em sua atuação didático-pedagógica, o educador precisa entender que é na coerência entre o que faz e o que diz que ocorre o efetivo encontro entre educador e educandos (FREIRE, 1996).

No segundo caso, com a aluna participante, evidenciou-se que a estratégia de superação deve ser, para ela, a interação com colegas e até com professores. Contudo, segundo seu relato, a iniciativa da interação é responsabilidade dos professores, pois, frequentemente, estes servem como espelho para os alunos. O depoimento a seguir representa essa visão da estudante:

Um professor disse até palavrão na sala [...]. Ele estava falando sobre a entrega de trabalhos e provas e avisou que, quem não fosse recebê-los na aula seguinte, não fosse também encher a paciência dele depois, pedindo nota. E aí ele falou o palavrão, [dizendo] também que não estava nem aí..., que não queria saber de alunos vindo reclamar já que não tinham vindo receber a nota. Eu achei desnecessário, aquilo. Ele poderia ter dado o recado de uma forma, digamos, mais humana e não, assim: sou o superior e não estou nem aí para vocês! 
Nesse evento de violência simbólica cometida pelo professor (BOURDIEU; PASSERON, 1992), a aluna e seus colegas permaneceram em silêncio. O professor praticou a violência e ninguém se manifestou. Independentemente desse desfecho para o mencionado episódio, os relatos da participante evidenciaram que, para esta, somente pela interação entre alunos e professores haverá o pronunciamento dos estudantes, seja com críticas construtivas direcionadas a especificidades do processo educacional, seja com relação ao desenvolvimento deles. Ficou claro que, para ela, interagir é estabelecer diálogos enquanto intercâmbio de experiências. Que o professor deve passar suas vivências profissionais e de vida aos alunos, sem o que não é gerado o clima propício à manifestação de opiniões. Que a boa interação ocorre quando uns e outros constroem atitudes positivas, sendo compatível com a pedagogia dialógica (FREIRE, 1996, 2011).

\section{Oportunidade e resiliência}

Nos terceiro e quarto casos, Oportunidade e Resiliência, o aluno e a aluna participantes são egressos de uma universidade particular, onde, em 2016, cada um deles concluiu um curso de graduação. No primeiro caso, para vencer o silêncio, o aluno informou que "corria atrás" de soluções para problemas do curso, valendo-se de oportunidades oferecidas por este para se desenvolver. Ao ser perguntado se, na interação com um professor por ele mencionado, havia abertura ao diálogo, ele respondeu:

Eu conversava, sim, caso o professor desse uma liberdade. Eu percebia que, quando ele queria dar conteúdo e não dava oportunidade, então, eu ficava na minha, tirava dúvida quando possível. Mas, quando há oportunidade, eu discuto, debato, tiro dúvida... [Na verdade,] eu me dava bem com os professores; só [com relação a] alguns dos conteúdos, eu tinha dificuldades! [Nesse caso,] eu tirava dúvida e corria atrás para estar me aperfeiçoando.

Há nessa resposta, clara presença da herança cultural do participante (BOURDIEU; PASSERON, 1964). Possivelmente, ele tenha aprendido, em casa, que precisa aproveitar oportunidades de abertura para manifestar-se e seguir com uma formação mais humana e, na escola, que o professor é quem escolhe e determina os momentos de formar-se. Ficou evidenciado, pelos relatos, que ele entende a importância de articular informação e formação. Pareceu ser essa a dinâmica percebida pelo aluno, não pelo professor.

Já o segundo caso revelou a presença da resiliência (TAVARES, 2002), como estratégia de superação. A egressa relatou situações emblemáticas de violência 
e tentativas de anular o aluno na sala de aula, nem sempre concretizável, caso a vítima tenha capacidade de rápida recuperação:

$1^{\text {a }}$ Situação: Enquanto a gente tinha uma professora que dava todo o suporte pra você entender e aprender, outras te desestimulavam.

$2^{\text {a }}$ Situação: Se seu problema é com o professor, resolva com ele e eu sempre tive isso muito fixo na minha cabeça. A gente teve problema de turma com o professor; eu tentei resolver com ele, não deu certo. Então, eu tive que procurar a coordenadora.

$3^{\text {a }}$ Situação: Havia um colega que tinha problema na fala e, toda vez que falava, os colegas zombavam dele. [Alguns professores interferiam, outros não].

$4^{\mathrm{a}}$ Situação: Numa apresentação do professor, eu questionei e ele me chamou de 'cavalinho' [...] e eu falei 'você é um babaca' [um tonto, um bobo]. Retruquei. Eu não era de ficar calada. Eu levei pra coordenação. A coordenadora [substituta] veio à sala. Ela e o professor ficaram falando lá em cima [do estrado]. Essa parte foi a mais chocante em meu curso. Com isso, eu me calei nas outras aulas com esse professor. Para tirar dúvidas, eu recorria a outras professoras. Eu dizia 'bom dia', porque minha mãe me ensinou a dar bom dia.

Como é possível observar, a aluna não desistia de se desenvolver plenamente. Apesar das dificuldades durante o curso, manteve-se firme e em atitude crítica. Com efeito, ela agia como Bernadette, a personagem em Gaulejac (2008), que, elaborando sonhos a partir de uma fotonovela, abre portas à criticidade e se revolta. Em seu relato, a aluna não atribui culpa aos professores, à universidade ou aos colegas pelos problemas afetos à sua formação; ao contrário, antes de identificar responsabilidades, evidenciou assumir-se como alguém capaz de resolvê-los.

Para Tavares (2002), quem se conduz dessa maneira responde aos desafios e dificuldades com consistência, flexibilidade, otimismo e equilíbrio, sendo capaz de dominar as pressões do contexto social no qual se insere. Em escala mais larga, segundo o autor, tal pessoa contribui para a construção de sociedades mais resilientes. Estas "implicam o desenvolvimento de atitudes que passam pela articulação de componentes cognitivos, afetivos e volitivos" (p. 66), algo próximo do que se espera da atuação de educadores. Estes, quando agem desse 
modo, encontram o apoio que humaniza naquilo que Freire $(1996,2011)$ chama de travessia - que é a capacidade de aproximar condições negativas de vida dos alunos para promover mudanças nas estruturas às quais eles estão submetidos.

\section{Compenetração e contextualização}

Nos últimos dois casos, Compenetração e Contextualização, o aluno e a aluna cursam graduação numa universidade pública. Evidenciou-se, no primeiro caso, a relevância de se poder contar, durante a graduação, com experiências de vida capazes de contribuir para a própria formação. De acordo com o participante, a formação abrange mais do que o mero ensino de conteúdos pela família ou escola, ou pela própria vida em situações específicas. $\mathrm{O}$ aluno se mostrou bastante persuadido da necessidade de manifestar-se nos processos educativos, senão, segundo ele, escapam momentos para uma formação mais ampla. Uma persuasão que, aparentemente, advém de sua capacidade de vincular experiências. Ao relatar porque se considera um aluno participativo e crítico, ofereceu as seguintes informações:

Primeiramente, minha família - a minha mãe, principalmente, que sempre disse que, se eu não concordar com alguma coisa, desejar algo diferente, se eu ficar calado, não vai resolver; ensinou-me que, se eu estivesse incomodado com alguma coisa, eu devia me expressar. Em segundo lugar, minha formação escolar, mesmo porque eu tive a sorte de ter muitos professores bons, preocupados não só com o conteúdo, mas com essa formação do aluno, de cidadão; eles também reforçavam essa ideia de que a gente não está ali para ficar só calado e aceitando tudo. Os outros fatores foram as leituras e experiências que eu tive, que me mostraram, realmente, que, no mundo onde a gente vive, não tem como você ficar passivo lá, recebendo tudo o que vem.

A convicção demonstrada nesse relato de que a formação integral se situa no encontro entre três atuações - família, escola e ele próprio - ressalta a compenetração do estudante como estratégia relevante à saída do silêncio durante $\mathrm{o}$ ato educativo. Processando informações recebidas e, indo em caminho inverso, de dentro para fora, o jovem estudante se tornará visível pela fala manifestada. Nesse sentido, a escola deve compreender que cada ser humano, com o qual lida em seu cotidiano, precisa ser tomado em suas potencialidades e tido como capaz de vincular experiências. Por isso mesmo, Alves (2001, p. 38-39) afirmava reiteradamente que a escola não é linha de montagem, com professores obstinados em adicionar saberes e habilidades sobre os alunos para transformá-los num produto final: 
O objeto original que entrou na linha de montagem chamada escola (naquele momento ele chamava 'criança') perdeu totalmente a visibilidade e se revela, então, como um simples suporte para os saberes-habilidades que a ele foram acrescentados durante o processo.

No segundo caso, o que contou com os relatos de uma aluna, evidenciou-se que, para a formação integral, torna-se relevante manter-se contextualizado. Sem isso, a participação na sala de aula fica reduzida:

Eu, particularmente, só me pronuncio e falo quando é um assunto que eu tenho domínio, certeza e que eu consiga debater plenamente; que seja do meu interesse.

Ficou claro que a ausência de informações, capazes de situar os alunos sobre assuntos desenvolvidos pelo professor, interfere no desejo de participar da aula. Segundo a aluna, em determinado período do curso:

Havia $50 \%$ de formandos [dentre eles, a aluna] e 50\% de calouros. [Estes] não deixavam a gente falar. Eles queriam mostrar para o professor que eles eram inteligentes [...] e a gente ficava pensando, 'meu Deus, cala a boca, cara, pra que isso?'.

Como se constata, a falta de informações levava a estudante entrevistada a ficar calada. Aqui não está a se referir à primazia da informação, e sim à articulação desta com a formação, contribuindo para a contextualização dos alunos. Nesse sentido, Coll et al. (1998) explicam que é necessário articular conteúdos conceituais, procedimentais e atitudinais durante o processo educacional. Isso contribui para que os alunos saiam do silêncio porque, consequentemente e, num processo simultâneo, eles entendem os assuntos desenvolvidos pelo professor, sabem para que estes servirão e percebem como eles poderão alterar modos de ser e agir.

\section{Percepções sobre os dramas de colegas e de professores}

Com os resultados e análises, elaborou-se um quadro, contendo percepções dos participantes sobre si, colegas e professores, relacionadas com a formação para a integralidade humana (ver Quadro 2).

Conforme o Quadro 2, os participantes se preocupam com os dramas de colegas e de professores nos contextos educativos pesquisados. Uma preocupação inserida 
Quadro 2. Percepções dos participantes.

\begin{tabular}{|l|c|c|c|}
\hline \multirow{2}{*}{ Casos } & \multicolumn{2}{|c|}{ Percepção dos participantes } \\
\cline { 2 - 4 } 1 & $\begin{array}{c}\text { Coerente, influenciável pelo } \\
\text { histórico familiar (docência) } \\
\text { e pelo perfil dos colegas. }\end{array}$ & Desinteressados. & $\begin{array}{c}\text { Alguns problematizam, } \\
\text { contribuindo para o } \\
\text { desenvolvimento dos } \\
\text { alunos. }\end{array}$ \\
\hline 2 & $\begin{array}{c}\text { Observadora, influenciável } \\
\text { pelas condutas favoráveis } \\
\text { ao desenvolvimento pleno. }\end{array}$ & Acomodados. & Preocupam-se em informar. \\
\hline 3 & $\begin{array}{c}\text { Atento às oportunidades de } \\
\text { aprender/ desenvolver-se. }\end{array}$ & Desinteressados. & $\begin{array}{c}\text { Priorizam o cumprimento } \\
\text { da grade curricular. Alguns } \\
\text { dinamizam a aula, aliando } \\
\text { teoria e prática. }\end{array}$ \\
\hline 4 & $\begin{array}{c}\text { Aberta ao diálogo. } \\
\text { Confronta situações de } \\
\text { injustiça. }\end{array}$ & Alheios. & $\begin{array}{c}\text { Preocupam-se em cumprir } \\
\text { normas da instituição. } \\
\text { Alguns são grosseiros. } \\
\text { Muitos estão cansados. }\end{array}$ \\
\hline 5 & $\begin{array}{c}\text { Influenciável pelas } \\
\text { experiências de vida e } \\
\text { escolar. }\end{array}$ & Acomodados. & $\begin{array}{c}\text { Professores das ciências } \\
\text { matemáticas tendem a só } \\
\text { informar. Os das sociais } \\
\text { incluem formação. }\end{array}$ \\
\hline 6 & $\begin{array}{c}\text { Situada com relação ao } \\
\text { contexto social. }\end{array}$ & Amedrontados. & $\begin{array}{c}\text { Compreensivos. Alguns são } \\
\text { grosseiros. }\end{array}$ \\
\hline
\end{tabular}

Fonte: elaboração dos autores (2017).

no seguinte cenário: o par violência-exclusão leva os colegas ao alheamento quanto ao tema do desenvolvimento pleno, conduzindo o olhar deles para a aquisição de notas em provas e, eventualmente, à capacitação para o trabalho; esse par mantém, com o silêncio, uma relação dialética, que alimenta a priorização de informações, e não a articulação destas com a formação.

Isso parece ocorrer conforme as conclusões de Morais (2011) sobre a educação superior. Para o autor, enquanto as instituições privadas oferecem aos estudantes, em ambientes de ética precária, o estritamente necessário para a formação de bacharéis e licenciados que, no fim dos cursos, mal conseguem dominar a língua portuguesa; as escolas públicas de ensino superior, por sua vez, mergulham na burocracia e manobras políticas, obrigando os professores a aprovar altos percentuais de alunos, ainda que estes não tenham adquirido a formação pretendida ou anunciada.

De todo modo, a mencionada preocupação dos estudantes é recurso não aproveitado para impulsionar e estabelecer a pedagogia dialógica. Em termos freireanos, esse 
aproveitamento poderia ser utilizado no dia a dia da ação docente, contribuindo para eliminar a contradição opressor-oprimido (FREIRE, 2011). A consciência dos participantes quanto ao contexto educacional no qual se inserem leva à percepção de desinteresse, acomodação e até medo por parte dos colegas; conduz à percepção de que há, por parte dos professores, a obrigação de cumprirem tarefas ditadas pela instituição, não obstante a necessidade de terem/buscarem uma formação continuada.

Sair desse circuito não é simples e são várias as propostas de solução. Nesse sentido, Nóvoa (2009), com relação aos cursos de formação de professores, sugere alternativas traduzidas como prática, profissão, pessoa, partilha e público. Ressalte-se a ideia de disposição, colocada pelo autor, em vez de atributos e competências, posto que a formação é uma construção cultural. Com efeito, sem disposição para promover mudanças, dialogar e aproximar-se dos alunos, o educador parece desaparecer no horizonte educativo. Em seu lugar, resta o mero instrutor, pondo-se à distância as premissas dos quatro pilares da educação para o século XXI (DELORS et al., 1998). No limite, alunos ficam invisíveis, silenciam-se.

\section{Conclusão}

Mergulhados no mundo das informações, sem liberdade para manifestar-se sobre sua formação mais ampla, jovens universitários parecem perambular solitários, uns correndo atrás do título, outros, não só disto, mas também de sentido. Estar cada um por si parece ser a norma. Parte deles, atada a informações técnicas, obviamente necessárias à formação profissional, se ressente de mediações que conduzam à formação mais rica, capaz de situar melhor as pessoas num mundo globalizado. Efetivamente, o momento histórico atual exige um novo tipo de informação, pelo que os percursos comunicativos, baseados na livre expressão, poderiam viabilizar uma formação humana diferenciada. Ocorreria como numa espiral, em que os pontos de chegada se nivelam, mas, mantendo-se a diferença quanto ao ponto de partida. Nessa diferença, o momento da transformação se faz presente, podendo remeter estudantes e professores para o futuro.

Entretanto, há indicativos de que parte desses estudantes se priva do direito à expressão, apesar do discurso atual de respeito à diversidade. No ambiente acadêmico, este trabalho evidenciou, sopesados os limites da pesquisa e, sem aprofundar questões estruturais - não ficou no esquecimento a grave crise das condições de trabalho em que se encontra a maioria dos professores deste país -, esse direito é subtraído dos estudantes, já vítimas de certas violências. Com alguma frequência, há grosserias por parte de quem deveria educar; há 
desqualificações de quem deveria dar atenção. Assim, excluem-se os alunos, pois ficam invisíveis aspectos humanos que deveriam estar mais presentes: a crítica construtiva, o feedback, o compartilhamento e assim por diante. $\dot{E}$, de fato, o silêncio ontológico.

O conjunto de tais aspectos, nessas condições, parece dar seguimento a uma espécie de invisibilidade humana. No dia a dia da escola, parece vivo o panoptismo foucaultiano, pelo que, na sala de aula, parte dos professores insiste na pretensão de tudo ver e, parte dos alunos, de continuarem na condição de serem observados em tudo e o tempo todo - permaneceriam ativos os tempos medievais da vigilância e punição (FOUCAULT, 2014)? Igual ao muxarabi, janela de treliça que, tanto nas colônias latino-americanas, como nos reinos ibéricos, permitia a algumas mulheres ver a rua sem serem vistas, os processos burocráticos em sua homogeneização servem mais para esconder professores, menos para organizar a vida dos alunos. Distancia-se o diálogo; aproxima-se a opressão. Portanto, o estudante fica à mercê de caprichos, de ações que, em princípio, parecem boas para seu desenvolvimento pleno, mas, na verdade, são prejudiciais à sua liberdade de expressão. Fica à mercê do uso generalizado de informações que, não sendo aproveitadas para dar sentido, podem renegar saberes.

Contudo, há esperança, pois alguns alunos conseguem erguer-se. Como verdadeiros paladinos, levantam-se. Com sua atitude, oferecem oportunidades de aprendizado coletivo, com estratégias educacionais efetivamente transformadoras - sair do discurso, ir à prática. Nesse sentido, a pedagogia dialógica pode operar a travessia capaz de afastar a relação opressor-oprimido, rumo à esperança, quebrando barreiras imperceptíveis entre a fala do professor e a fala do aluno. É, de fato, a viabilização das possibilidades de superação do silêncio, traduzíveis em termos de inédito viável - a expressão freireana para designar o nível de conscientização dos indivíduos obtida por meio da vinculação entre experiências singulares e outras mais amplas (FREIRE, 2011). 


\title{
Young university students silent in the world of information: cases of liberation
}

\begin{abstract}
This article presents a research aiming to investigate strategies to overcome the logic of violence, exclusion and silence, to which young university students are submitted. These students are often in educational processes dissonant from usual intentions of providing full development. However, these curricular features contribute to strengthen the aforementioned logic. Among the students, there is a silence. The university needs to practice a dialogic education, rather than a monologic one. A multiple cases study, where each case was given a name - coherence, interaction, opportunity, resilience, rapport and contextualization-concluded that the moments of overcoming are potential transformative educational strategies.
\end{abstract}

Keywords: University. Violence. Exclusion. Silence. Liberation.

\section{Jóvenes universitarios en silencio en el mundo de la información: casos de liberación}

\section{Resumen}

Esta investigación tuvo como objetivo investigar estrategias de superación de la lógica de violencia, exclusión y silencio, a la que están sometidos jóvenes universitarios. Estos reciben mucha información, sufriendo procesos educativos disonantes de las proclamadas intenciones de desarrollo pleno, lo que favorece la mencionada lógica. En general, son percibidos como personas no críticas. Entonces, silencian. En vez de la educación monológica, la universidad necesita practicar la educación dialógica. Un estudio de casos múltiples, en el que cada caso único recibió un nombre - coherencia, interacción, oportunidad, resiliencia, compenetración y contextualización - concluyó que los momentos de superación son potenciales estrategias educativas transformadoras, que llevan del discurso a la práctica, de la opresión a la esperanza.

Palabras clave: Universidad. Violencia. Exclusión. Silencio. Liberación. 


\section{Referências}

ALVES, R. A escola com que sempre sonhei sem imaginar que pudesse existir. Campinas, SP: Papirus, 2001.

ARISTÓTELES. Ética a Nicômaco. In: Os pensadores: Aristóteles. São Paulo, SP: Nova Cultural, 1996. p. 117-320.

BARDIN, L. Análise de conteúdo. 5. ed. Lisboa: 70, 2009.

BAUMAN, Z. Identidade. Rio de Janeiro, RJ: Jorge Zahar, 2005.

. Los retos de la educación en la modernidad líquida. Barcelona:

Gedisa, 2007.

BERTEAUX, D. Los relatos de vida: perspectiva etnosociológica. Barcelona: Bellaterra, 2005.

BOURDIEU, P. O campo científico. In: BOURDIEU, P.; ORTIZ, R. (Org.). Pierre Bourdieu: sociologia. São Paulo, SP: Ática, 1994.

BOURDIEU, P.; PASSERON, J.-C. Les héritiers: les étudiants et la culture. Paris, Minuit, 1964.

. A reprodução: elementos para uma teoria do sistema de ensino. 3 . ed. Rio de Janeiro, RJ: Francisco Alves, 1992.

BRASIL. Lei $N^{\circ}$ 9.394, de 20 de dezembro de 1996. Estabelece as diretrizes e bases da educação nacional. Diário Oficial União, 23 dez. 1996

BRUNSSON, N. The consequences of decision-making. Oxford: Oxford University, 2007.

BUBER, M. Do diálogo e do dialógico. São Paulo, SP: Perspectiva, 1982.

COLL, C. et al. Os conteúdos na reforma: ensino e aprendizagem de conceitos, procedimentos e atitudes. Porto Alegre, RS: Artes Médicas, 1998.

DELORS, J. et al. Educação um tesouro a descobrir: relatório para a Unesco da comissão internacional sobre educação para o século XXI. Paris: Unesco, 1998.

DUBET, F. Sociologia da experiência. Lisboa: Instituto Piaget, 1994. 
ENGUITA, M. F. La educación en la encrucijada. Espanha: Fundación Santillana, 2016.

FOUCAULT, M. Vigiar e punir: nascimento da prisão. 42. ed. Petrópolis, RJ: Vozes, 2014.

FREIRE, P. Papel da educação na humanização. Revista Paz e Terra, São Paulo, n. 9, p. 123-32, 1969.

. Pedagogia da autonomia: saberes necessários à prática educativa. São Paulo, SP: Paz e Terra, 1996. . Pedagogia da esperança: um reencontro com a pedagogia do oprimido. 22. ed., São Paulo, SP: Paz e Terra, 2015.

. Pedagogia do oprimido. 50. ed. São Paulo, SP: Paz e Terra, 2011.

GAULEJAC, V. Les sources de la honte. Paris: Desclée de Brouwer, 2008.

GOMES, C. A.; LIRA, A. Aprender a convivir: cómo las escuelas hacen la diferencia. Revista Internacional Magisterio: Educación y Pedagogía, Bogotá, v. 44, p. 40-5, 2010.

HALL, S. A identidade cultural na pós-modernidade. 11. ed. Rio de Janeiro, RJ: DP\&A, 2011.

HEGEL, G. W. F. Fenomenologia do espírito. 2. ed. Petrópolis, RJ: Vozes, 2003.

MERRIAM, S. B. Qualitative research and case study applications in education. San Francisco, CA: Jossey-Bass, 1998.

MORAIS, R. Um abominável mundo novo? O ensino superior atual. São Paulo, SP: Paulus, 2011.

NÓVOA, A. Para uma formação de professores construída dentro da profissão. Revista de Educación, Madrid, n. 350, 2009.

ORGANIZAÇÃO DAS NAÇÕES UNIDAS - ONU. Resolution $N^{o}$. 36/28. International youth year: participation, development, peace. New York, NY, 1981. Disponível em: <http://www.un.org/french/ documents/view_doc.asp?symbol=A/RES/36/28\&Lang $=\mathrm{F}>$. Acesso em: 15 nov. 2018. 
ORGANIZAÇÃO DAS NAÇÕES UNIDAS - ONU. Declaração universal dos direitos humanos. Brasília, DF: Unesco, 1998. Disponível em: <http://unesdoc.unesco.org/images/0013/001394/139423por.pdf > . Acesso em: 15 nov. 2018.

PAZ, O. Signos em rotação. São Paulo, SP: Perspectiva, 1976.

STAKE, R. A arte da investigação com estudos de caso. 4. ed., Lisboa: Fundação Calouste Gulbenkian, 2016.

TAVARES, J. (Org.). Resiliência e educação. 3. ed. São Paulo, SP: Cortez. 2002.

TEIXEIRA, A. Educação no Brasil. 2. ed. São Paulo, SP: Companhia Nacional, 1976.

VASCONCELOS, I. C. O. Aprender a conviver, sem violência: o que dá certo e não dá certo? Ensaio: Avaliação e Políticas Públicas em Educação, Rio de Janeiro, v. 25, n. 97, p. 897-917, 2017. https://doi.org/10.1590/s010440362017002501180

VASCONCELOS, I. C. O.; GOMES, C. A. Pedagogia dialógica para democratizar a educação superior. Ensaio: Avaliação e Políticas Públicas em Educação, Rio de Janeiro, v. 24, n. 92, p. 579-608, 2016. https://doi. org/10.1590/S0104-40362016000300004

VASCONCELOS, I. C. O.; GOMES, C. A. C. A reprodução da reprodução sociocultural: sem crítica, com culpa e com primazia da informação. Revista Linhas, Florianópolis, v. 18, n. 37, p. 210-38, 2017. https://doi. org/10.5965/1984723818372017210

XIBERRAS, M. As teorias da exclusão: para uma construção do imaginário do desvio. Lisboa: Instituto Piaget, 1996.

YIN, R. K. Estudo de caso: planejamento e métodos. 4. ed. Porto Alegre, RS: Bookman, 2010. 


\section{Informações dos autores}

Ivar César Oliveira de Vasconcelos: Doutor em Educação. Professor do Programa de Pós-Graduação Stricto Sensu em Educação e pesquisador da Cátedra UNESCO de Juventude, Educação e Sociedade na Universidade Católica de Brasília (UCB). Professor titular do Instituto de Ciências Sociais e Comunicação da Universidade Paulista (UNIP). Contato:ivcov@hotmail.com

iD http://orcid.org/0000-0001-5186-8000

Adriana Lira: Doutora em Educação pela Universidade Católica de Brasília (UCB). Professora do curso de Pedagogia do Centro Universitário do Distrito Federal (UDF). Contato: liradrika@gmail.com

iD http://orcid.org/0000-0002-9692-5088

Iomar Pirangi Soares: Centro Educacional Sigma. Brasília, Distrito Federal, Brasil Mestrando em Educação pela Universidade Católica de Brasília (UCB). Professor da educação básica.Contato: iomarpsoares@gmail.com

iD http://orcid.org/0000-0002-5845-7439 